\title{
The anti-inflammatory effect of the platelet-rich plasma in the periodontal pocket
}

\author{
Lubaba A. Abdul Ameer ${ }^{1}$, Zainab J. Raheem ${ }^{1}$, Saif Saadedeen Abdulrazaq ${ }^{2}$, \\ Basima Gh. Ali ${ }^{1}$, Maysaa Mahdi Nasser ${ }^{3}$, Azza Wala Aldeen Khairi ${ }^{1}$
}

Correspondence: Dr. Saif Saadedeen Abdulrazaq

Email: saifdento@gmail.com

\author{
'Department of Periodontics, College of Dentistry, \\ University of Baghdad, Baghdad, Iraq, \\ ${ }^{2}$ Department of Oral and Maxillofacial Surgery, College \\ of Dentistry, University of Baghdad, Baghdad, Iraq, \\ ${ }^{3} \mathrm{AL}-$ Sader Dental Specialized Center, Baghdad, Iraq
}

\section{ABSTRACT}

Objective: Chronic periodontitis (CP) is a common inflammatory disease that causes destruction to the supporting tissues of the teeth. Many treatment modalities tried to stop the disease progression. Platelet-rich plasma (PRP) is one of the regenerative methods that used in adjunct to conventional periodontal treatment. The aim of this study was to evaluate the anti-inflammatory effect of PRP by monitoring the lymphocyte count before and after its application to the periodontal pocket. Materials and Methods: Twenty patients, with $\mathrm{CP}$ and a pocket depth equal to or deeper than $4 \mathrm{~mm}$, subjected to scaling, root planing, and PRP injection into the pocket. The lymphocyte count measured before and after 1 month from PRP application. Clinical periodontal parameters were taken during two visits (1 month apart), with customized stent fabrication. Results: All clinical periodontal parameters showed a reduction in their value following 1 month of PRP application. . There was a noticeable reduction in lymphocyte count from (mean 2.47 \pm 0.91 ) to (mean 1.94 $\pm 0.77)$. Conclusion: In addition to its traditional uses, PRP has a great role in the periodontal treatment by its anti-inflammatory effect.

Key words: Lymphocyte count, periodontal pocket, platelet-rich plasma

\section{INTRODUCTION}

Chronic periodontitis (CP) is "an infectious disease resulting in inflammation within the supporting tissues of the teeth, progressive attachment, and bone loss." [1]

Progression of $\mathrm{CP}$ is depending on the virulent microorganisms and host response to pathogenic infection. ${ }^{[2]}$ Scaling and root planing considered as a conventional nonsurgical treatment of periodontal diseases. ${ }^{[3]}$ Platelet-rich plasma (PRP) injection, concentrated platelets from autologous blood activated by the addition of thrombin and calcium, works to improve periodontal ligament cell production and

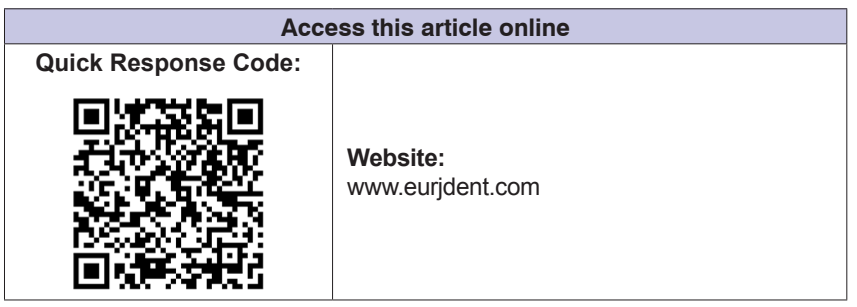

protein development, which will lead to accelerating periodontal wound healing. ${ }^{[4]}$

When PRP activated, the growth factors and proteins released to the local environment, accelerating postoperative wound healing and tissue repair. ${ }^{[5]}$

Examination of the connective tissue during periodontal disease under a microscope reveals a disruption of the normal anatomy of the connective tissues by a huge infiltration of numerous defense cells, particularly neutrophils, macrophages, plasma

This is an open access journal, and articles are distributed under the terms of the Creative Commons Attribution-NonCommercial-ShareAlike 4.0 License, which allows others to remix, tweak, and build upon the work non-commercially, as long as appropriate credit is given and the new creations are licensed under the identical terms.

For reprints contact: reprints@medknow.com

How to cite this article: Abdul Ameer LA, Raheem ZJ, Abdulrazaq SS, Ali BG, Nasser MM, Aldeen Khairi AW. The anti-inflammatory effect of the platelet-rich plasma in the periodontal pocket. Eur $\mathrm{J}$ Dent 2018;12:528-31.

DOI: 10.4103/ejd.ejd_49_18 
cells, and lymphocytes with the extracellular release of their destructive enzymes. ${ }^{[6]}$ Changes in leukocyte, neutrophil, and lymphocyte numbers used as a healing monitor during periodontal treatment. ${ }^{[7]}$

Theaim of thisstudy was toevaluatetheanti-inflammatory effect of PRP in the treatment of pockets, as an adjunct to scaling and root planing, by measuring the lymphocyte count before and after treatment.

\section{MATERIALS AND METHODS}

\section{Sample selection and study design}

Twenty patients involved in this study. All patients had $\mathrm{CP}$, according to the periodontal disease classification system of the American Academy of Periodontology, ${ }^{[8]}$ and a pocket depth equal to or more than $4 \mathrm{~mm}$. All patients have no history of any systemic diseases. Patients' age ranged from 25 to 50 years. The gender distributed equally between females and males.

The exclusion criteria included smokers, alcohol drinkers, pregnant women, a pathological condition in the area, and patients on medications such as anti-inflammatory drugs or antibiotic treatments within the past 3 months. All these conditions affect the lymphocyte count.

\section{Patient preparation and stent fabrication}

Informed consents were taken. All patients subjected to the conventional periodontal treatment such as motivation, instruction, and supragingival and subgingival scaling. Impressions were taken for occlusal stent fabrication to standardize the readings for the same site throughout the visits. The stent was made from thermal-forming splint/copolyester with 1-mm thickness.

\section{Clinical periodontal parameter recording}

In the first visit, before root planing, periodontal parameters such as plaque index (PLI), gingival index (GI), bleeding on probing (BOP), probing pocket depth (PPD), and relative attachment level (RAL) were recorded as a baseline before PRP application. The stent adjusted to cover two-thirds of the crown. RAL was recorded from the lower border of the stent to the deepest point of the pocket. In the second visit, after 1 month from PRP application, all periodontal parameters were recorded again.

\section{Platelet-rich plasma preparation}

Seven milliliters of blood was taken from each patient at the first visit to prepare the PRP and to estimate lymphocyte count. One milliliter of blood was used to estimate the lymphocyte count, and $6 \mathrm{ml}$ of blood was distributed into three sodium citrate vacuum tubes (each tube with $2 \mathrm{ml}$ ), with a gentle rocking of the tubes back and forth several times to ensure the complete incorporation of blood with the anticoagulant. The blood then was subjected to centrifuge at two cycles. ${ }^{[9]}$ The first cycle was at 3000 rounds/min (rpm) for $5 \mathrm{~min}$, and then, the plasma supernatant layer (which contains platelets and white blood cells) was taken and put it in a plain tube ready to the second cycle. The second cycle was at $3500 \mathrm{rpm}$ for $15 \mathrm{~min}$. The upper two-thirds of the solution was discarded and the lower third (which contains the red spot and platelet pallets) was taken as a pure PRP.

Using insulin syringe, $10 \%$ of the syringe volume was filled with calcium chloride (activator) and 90\% by PRP added slowly, with forth and back motion to mix the syringe contents.

\section{Platelet-rich plasma application}

After anesthetizing the affected tooth, root planing was done using universal curette. PRP was injected into the pocket. Slight pressure applied to the area using moist gauze for $5 \mathrm{~min}$, for a clot to be formed. ${ }^{[10]}$

\section{Lymphocyte count}

In the first visit, $1 \mathrm{ml}$ was used to estimate lymphocyte count. In the second visit, $1 \mathrm{ml}$ of blood also used to estimate lymphocyte count after 1 month from PRP application.

\section{Statistical analysis}

Statistical analysis was made with the Statistical Package for the Social Sciences (version 20.0; Armonk, New York, 2011). ${ }^{[11]}$ Both descriptive (mean, standard deviation, and percentage) and inferential statistics ( $t$-test and Pearson correlation) were used. The relationship considered statistically significant if $P<0.05$.

\section{RESULTS}

The clinical periodontal parameters (PLI, GI, BOP, PPD, and RAL) were shown a reduction in their mean values after 1 month from the treatment with the PRP, with a highly significant difference [Table 1]. During this period (1 month), no complications had been observed. 
There was a marked reduction in the lymphocyte count at baseline (2.47 \pm 0.91$)$ and after 1 month $(1.94 \pm 0.77)$, with a highly significant difference $(P=<0.000)$ between them [Table 2].

When the amount of plaque increased, the lymphocyte count is also increased leading to increase in the gingival inflammation and destruction of the periodontium [Table 3].

\section{DISCUSSION}

Many articles had studied the regeneration property of PRP. ${ }^{[12]}$ El-Sharkawy et al., in 2007, demonstrated that PRP may suppress cytokine release, limit inflammation, and promote tissue regeneration. ${ }^{[13]}$ Tavassoli-Hojjati et al., in 2016, concluded that the growth-stimulating effect of PRP is dose dependent with the best results in low concentrations. ${ }^{[14]}$ On the other hand, the results of in vitro study by Kobayashi et al., in 2017, suggest that PRP promoted gingival fibroblast migration and proliferation but have little to no effect on osteoblast differentiation. ${ }^{[15]}$

\begin{tabular}{|c|c|c|c|c|}
\hline \multirow[t]{2}{*}{ Variables } & \multicolumn{2}{|c|}{ Mean $\pm S D$} & \multirow[t]{2}{*}{$t^{*}$} & \multirow[t]{2}{*}{$P$} \\
\hline & Baseline & After 1 month & & \\
\hline PLI & $0.84 \pm 0.22$ & $0.76 \pm 0.21$ & 17.19 & $<0.000(\mathrm{HS})$ \\
\hline GI & $1.75 \pm 0.25$ & $1.38 \pm 0.20$ & 30.84 & $<0.000(\mathrm{HS})$ \\
\hline BOP \% & $74.58 \pm 28.22$ & $38.82 \pm 21.50$ & 4.50 & $<0.000(\mathrm{HS})$ \\
\hline PPD & $5.13 \pm 0.67$ & $4.41 \pm 0.73$ & 33.84 & $<0.000(\mathrm{HS})$ \\
\hline RAL & $8.72 \pm 2.27$ & $7.89 \pm 2.31$ & 17.19 & $<0.000(\mathrm{HS})$ \\
\hline
\end{tabular}

\begin{tabular}{|c|c|c|c|c|}
\hline \multirow[t]{2}{*}{ Variables } & \multicolumn{2}{|c|}{ Mean \pm SD } & \multirow[t]{2}{*}{$t^{*}$} & \multirow[t]{2}{*}{$P$} \\
\hline & Baseline & After 1 month & & \\
\hline Lymphocyte count & $2.47 \pm 0.91$ & $1.94 \pm 0.77$ & 12.14 & $<0.000(\mathrm{HS})$ \\
\hline
\end{tabular}

\begin{tabular}{|c|c|c|c|c|c|c|}
\hline Variables & $\begin{array}{l}\text { Statistical } \\
\text { analysis }\end{array}$ & PLI & GI & BOP & PPD & RAL \\
\hline \multirow{2}{*}{$\begin{array}{l}\text { Lymphocyte } \\
\text { count }\end{array}$} & $r$ & 0.24 & 0.15 & 0.21 & 0.01 & -0.14 \\
\hline & $P$ & 0.30 & 0.50 & 0.36 & 0.93 & 0.55 \\
\hline
\end{tabular}

Our study results showed a decrease in the mean value of clinical periodontal parameters (PLI, GI, BOP, PPD, and RAL) after 1 month of using PRP. This result could be due to the growth factors that released from the platelets which accelerate the healing process. ${ }^{[10,13]}$

There was a noticeable decrease in lymphocyte concentration after PRP treatment; this is because the platelets in the PRP release a considerable amount of RANTES (a major monocyte chemoattractant) from its alpha-granules. RANTES also inhibits many cytokines released by basophils, ${ }^{[10,16]}$ resolution of inflammation, and decrease in the concentration of lipoxin $\mathrm{A}_{4}$ (anti-inflammatory marker) which in turn depress the number of inflammatory cells. ${ }^{[13]}$

Concerning the correlation between the lymphocyte count and clinical periodontal parameters, the study revealed a direct proportion between lymphocyte count and PLI, GI, BOP, and PPD; when the PLI, GI, and BOP scores increase, they indicate that the bacterial toxins, the inflammatory process, and the lymphocyte count are also increased.

\section{CONCLUSION}

PRP has anti-inflammatory properties; it decreases the inflammation and accelerates the healing process. As a result, it will decrease the pocket depth and increase the attachment gain.

\section{Financial support and sponsorship \\ Nil.}

\section{Conflicts of interest}

There are no conflicts of interest.

\section{REFERENCES}

1. Novak MJ, Novak KF. Chronic periodontitis. In: Newman MG, Takei HH, Klokkevold ER, Carranza FA, editors. Carranza's Clinical Periodontology. $11^{\text {th }}$ ed. Missouri: Saunders, An Imprint of Elsevier Inc.; 2012. p. 160.

2. Craig RG, Yip JK, Mijares DQ, LeGeros RZ, Socransky SS, Haffajee AD, et al. Progression of destructive periodontal diseases in three urban minority populations: Role of clinical and demographic factors. J Clin Periodontol 2003;30:1075-83.

3. Anitua E, Andia I, Ardanza B, Nurden P, Nurden AT. Autologous platelets as a source of proteins for healing and tissue regeneration. Thromb Haemost 2004;91:4-15.

4. Tözüm TF, Keçeli HG, Serper A, Tuncel B. Intentional replantation for a periodontally involved hopeless incisor by using autologous platelet-rich plasma. Oral Surg Oral Med Oral Pathol Oral Radiol Endod 2006;101:e119-24.

5. Pejcić A, Kesić L, Pesić Z, Mirković D, Stojanović M. White blood cell count in different stages of chronic periodontitis. Acta Clin Croat 2011;50:159-67.

6. Heitz-Mayfield LJ, Trombelli L, Heitz F, Needleman I, Moles D. A systematic review of the effect of surgical debridement vs 
non-surgical debridement for the treatment of chronic periodontitis. J Clin Periodontol 2002;29 Suppl 3:92-102.

7. Hanna R, Trejo PM, Weltman RL. Treatment of intrabony defects with bovine-derived xenograft alone and in combination with platelet-rich plasma: A randomized clinical trial. J Periodontol 2004;75:1668-77.

8. Lindhe J, Ranney R, Lamster I, Charles A, Chung CP, Flemmig T, et al. Consensus report: chronic periodontitis. Annals Periodontol. 1999;4:38.

9. Jo CH, Roh YH, Kim JE, Shin S, Yoon KS. Optimizing platelet-rich plasma gel formation by varying time and gravitational forces during centrifugation. J Oral Implantol 2013;39:525-32.

10. Agarwal A, Gupta ND. Platelet-rich plasma combined with decalcified freeze-dried bone allograft for the treatment of noncontained human intrabony periodontal defects: A randomized controlled split-mouth study. Int J Periodontics Restorative Dent 2014;34:705-11.

11. International Business Machines Corporation. Released International Business Machines SPSS Statistics for Windows, Version 20.0. Armonk, NY: International Business Machines Corporation; 2011.
12. Roselló-Camps À, Monje A, Lin GH, Khoshkam V, Chávez-Gatty M, Wang HL, et al. Platelet-rich plasma for periodontal regeneration in the treatment of intrabony defects: A meta-analysis on prospective clinical trials. Oral Surg Oral Med Oral Pathol Oral Radiol 2015;120:562-74.

13. El-Sharkawy H, Kantarci A, Deady J, Hasturk H, Liu H, Alshahat M, et al. Platelet-rich plasma: Growth factors and pro- and anti-inflammatory properties. J Periodontol 2007;78:661-9.

14. Tavassoli-Hojjati S, Sattari M, Ghasemi T, Ahmadi R, Mashayekhi A. Effect of platelet-rich plasma concentrations on the proliferation of periodontal cells: An in vitro study. Eur J Dent 2016;10:469-74.

15. Kobayashi E, Fujioka-Kobayashi M, Sculean A, Chappuis V, Buser D, Schaller B, et al. Effects of platelet rich plasma (PRP) on human gingival fibroblast, osteoblast and periodontal ligament cell behaviour. BMC Oral Health 2017;17:91.

16. Holme PA, Müller F, Solum NO, Brosstad F, Frøland SS, Aukrust P, et al. Enhanced activation of platelets with abnormal release of RANTES in human immunodeficiency virus type 1 infection. FASEB J 1998;12:79-89. 